\title{
CLINICAL MEASUREMENT OF VARUS-VALGUS DEFORMITY AFTER SUPRACONDYLAR FRACTURE OF THE HUMERUS
}

HARISH S. BHENDE

Supracondylar fractures of the humerus are common in childhood, and in less developed countries many late malunions are seen. A restricted range of elbow movement often makes it difficult to measure varus-valgus deformity clinically. This can be assessed from bony points but may be hindered by chronic swelling around the elbow. In these cases the pronation-supination range of the forearm is almost never restricted and can be used to measure the angle of varus-valgus deformity, since the arc of this range depends on the orientation of the lower end of the humerus.

Method. The patient is examined with both elbows at $90^{\circ}$ flexion, and the upper arms vertical. A rod is held in each hand, and the patient is asked to pronate fully and then to supinate both forearms (Figs 1 and 2). The maximum

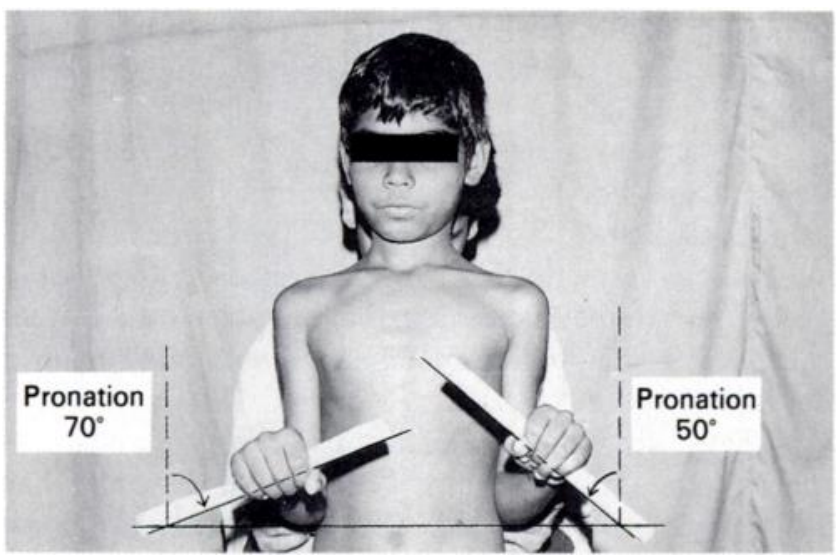

Fig. 1 condylar fracture of the humerus was reviewed. Radiographs were taken of both elbows and Baumann's angle recorded. The new clinical test was performed, angles being measured with a fluid-level goniometer. In the 38 patients with restriction of flexion-extension, the total range of pronation-supination on each side was recorded. Results. On the normal side, the average pronation angle was $80.7^{\circ} \mathrm{SD} 4.4$ and the average supination angle was 93.3 ${ }^{\circ} \mathrm{SD}$ 6.4. In the 38 cases of malunited fracture with an average of $35^{\circ}$ loss of extension the average pronationsupination arc was $173.0^{\circ} \mathrm{SD} 8.8$, as against $175.3^{\circ} \mathrm{SD} 7.69$ for the normal side, not a statistically significant difference. In all 60 cases, the mean clinical difference between sides was $32^{\circ}(10$ to 63$)$ and the mean radiological angulation was $32.6^{\circ}$ (15 to 53 ); in only two cases was

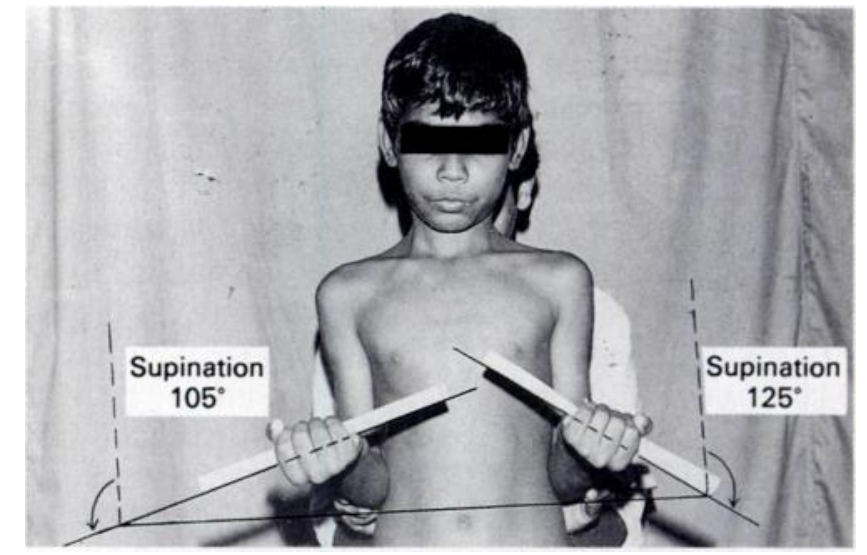

Fig. 2

Clinical examination of a patient with $20^{\circ}$ loss of pronation and $20^{\circ}$ increase in supination due to malunion of a left supracondylar fracture.

angle of each movement to the nearest $5^{\circ}$ is measured, and the injured and the normal limb are compared. The average between the increase in supination and the decrease in pronation equals the angle of varus malunion. In the rare valgus malunion, supination is reduced and pronation is increased, but the same principles apply. A consecutive series of 60 children with malunited supra-

H. S. Bhende, MS(Orth), DNB(Ortho), Lecturer

L. T. M. General Hospital, L. T. M. Medical College, Bombay 400022 , India.

C1994 British Editorial Society of Bone and Joint Surgery

0301-620X/94/2R95 $\$ 2.00$

J Bone Joint Surg [Br] 1994; 76-B:329-30.

Received 2 February 1993; Accepted 29 April 1993 the difference greater than $5^{\circ}$. Full details of the results are available from the author.

A paired $t$-test showed no significant difference between the radiological and the clinical measurements.

Discussion. When the elbow is flexed to $90^{\circ}$, the plane of pronation-supination of the forearm is perpendicular to the long axis of the humerus. The rod in the patient's hand will be horizontal in $90^{\circ}$ of pronation and in $90^{\circ}$ of supination. Tilting of the lower end of the humerus into valgus or varus, as in a malunited supracondylar fracture, will alter the position of this range of movement.

Many authors take maximal pronation and supination to be $90^{\circ}$ each (Turek 1984; Crenshaw 1987) but other smaller values have been reported (Morrey et al 1981). The average values of pronation and supination in this study were $80.7^{\circ}$ and $93.3^{\circ}$ respectively, but the method 
uses a rod in the fist and therefore some wrist movement may be included. Since the test compares abnormal and normal sides the actual range is unimportant.

Advantages of the method are that the measurements are made in a flexed position and that rotational malalignment at the fracture site does not affect the result. The absolute measurement of the deformity is also uninfluenced by the carrying angle of the elbow; this must affect measurements made by comparing the axes of forearm and arm with the elbow extended.

The finding that the total range of pronationsupination is usually normal despite restricted flexion extension can be explained. The restriction to extension is usually due to extra-articular involvement of the capsule, biceps, triceps and brachialis rather than to intraarticular damage which would restrict both planes of movement. Any mechanical block in the olecranon or coronoid fossae will restrict flexion-extension movement without affecting pronation-supination. Any injury directly involving the joint surfaces may cause restriction of pronation-supination, but this will be obvious during the test.

No benefits in any form have been received or will be received from a commercial party related directly or indirectly to the subject of this article.

\section{REFERENCES}

Crenshaw, AH. Campbell's operative orthopaedics. Seventh ed. St Louis: CV Mosby Co, 1987.

Morrey BF, Askew LJ, An KN, Chao EY. A biomechanical study of normal functional elbow motion. J Bone Joint Surg [Am] 1981; 63 A:872-7.

Turek S. Orthopaedics: principles and their application. Third ed. Philadelphia, etc: JB Lippincott Co, 1977:756.

\section{A NEW TYPE OF CRUSH INJURY OF THE CARPUS}

\section{J. VEGTER, J. H. J. M. BESSEMS}

Severe crush injuries of the carpus are rare. They are usually characterised by longitudinal splitting extending between the metacarpals, with the central carpal column of the lunate, capitate and third metacarpal remaining stable (Garcia-Elias et al 1989). We describe a crush injury of the carpus which resulted in displacement of both the central and the medial carpal columns.

Case report. An 18-year-old right-handed man injured his left hand and wrist by crushing in a rolling press. Management of the bone injury was postponed because of severe soft-tissue damage and it was not until two weeks after the injury that he was referred to our orthopaedic department. In addition to swelling, contusion and laceration of the skin on the volar and radial sides of the distal arm and wrist, the webspace between the third and fourth metacarpals was widened and there was prominence of the thenar eminence. There were no signs of vascular or nerve injury.

An anteroposterior radiograph showed a diastasis between the third and fourth metacarpals and between the central and ulnar carpal columns. There was also a fracture of the trapezoid (Fig. 1a). The lateral radiograph showed volar displacement of the scaphoid, lunate, capitate and

J. Vegter, MD, Orthopaedic Surgeon

J. H. J. M. Bessems, MD, Orthopaedic Resident

Elkerliek Hospital Helmond-Deurne, Wesselmanlaan 25, 5707 HA Helmond, The Netherlands.

Correspondence to Dr J. Vegter.

(C)1994 British Editorial Society of Bone and Joint Surgery

0301-62OX/94/2R89 $\$ 2.00$

J Bone Joint Surg [Br] 1994; 76-B:330-1.

Received 3 March 1993; Accepted 2 April 1993 trapezoid with respect to the triquetrum and the hamate (Fig. 1b). The relationship of the triquetrum to the hamate appeared normal.

Reduction of the dislocation was achieved under regional anaesthesia and maintained by external fixation, using a medium-C-Hoffman fixator. Two weeks later the skin defect on the distal arm was treated by a split-skin graft. The external fixator remained in place for a further four weeks after which mobilisation was allowed in a detachable splint.

Three years later the patient had no complaints. The wrist extended $75^{\circ}$ and flexed $80^{\circ}$; radial deviation was $15^{\circ}$ and ulnar deviation $25^{\circ}$. The strength of grip of the left hand was $90 \%$ of the right. The anteroposterior radiograph showed no signs of intercarpal or metacarpal diastasis (Fig. 2a), and the symmetrical lateral or 'prayer' views (Vegter 1987) showed no carpal instability (Figs $2 b, c)$.

Discussion. Traumatic axial dislocations of the carpus have been classified according to the site of disruption of the carpal arch (Garcia-Elias et al 1989). In the axialulnar type the longitudinal split is on the ulnar side of the capitate; the ulnar carpal column and corresponding fourth and fifth metacarpals are displaced towards the ulnar side and proximally. In the axial-radial type the disruption is on the radial side of the capitate and the radial carpal column and the first and second metacarpals are displaced proximally and radially. Both forms of derangement may coexist.

In our case, the axial split between the central and the ulnar carpal columns was associated with a reverse pattern of dislocation, as shown by the lateral radiograph. The volar and proximal displacement of the capitate, the 